GLOBAL JOURNAL OF PURE AND APPLIED SCIENCES VOL. 26, 2020: 1-8

COPYRIGHTC BACHUDO SCIENCE CO. LTD PRINTED IN NIGERIA ISSN 1118-0579 www.globaljournalseries.com, Email: info@globaljournalseries.com

\title{
EFFECT OF ETHANOL EXTRACT OF AFRAMOMUM ANGUSTIFOLIUM SEEDS ON POTASSIUM BROMATE INDUCED LIVER AND KIDNEY DAMAGE IN WISTAR RATS
}

\author{
EBHOHIMEN, I. E., EBHOMIELEN, J. O., EDEMHANRIA, L., OSAGIE, A. O. AND OMORUYI, J. I.
}

(Received 16 January 2019; Revision Accepted 27 March 2020)

\begin{abstract}
The continued use of potassium bromate in some food and cosmetic products in Nigeria against regulatory provision has continually exposed Nigerians to its deleterious effect. The mechanism of bromate induced damage in the liver and kidney is through oxidative stress. Phytochemicals have antioxidant capacity and have gained research interest in the management of oxidative stress. In this study, the effect of the ethanol extract of Aframomum angustifolium seed on kidney and liver damage induced by exposure to an acute dose of potassium bromate was measured using appropriate biomarkers. Eighteen male Wistar rats, randomly divided into 3 groups were used for the study. Group I (normal control) received distilled $\mathrm{H}_{2} \mathrm{O}$; Group II (positive control) received $400 \mathrm{mg} / \mathrm{kgbw}$ bromate once while Group III (test) received same acute dose as Group II but thereafter treated with an oral dose of ethanol extract $(750 \mathrm{mg} / \mathrm{kgbw})$ for 10days. Half the populations of each group were sacrificed on day 3 while the remaining was sacrificed on day 10 of treatment. Liver and kidney tissues as well as blood samples were collected for analysis. Biochemical parameters; malondialdehyde, creatinine, electrolytes $\left(\mathrm{Na}^{+}\right.$and $\left.\mathrm{K}^{+}\right)$concentration as well as catalase, alanine aminotransferase and alkaline phosphatase activities were measured using standard spectrophotometric procedures. In the kidney tissue, malondialdehyde concentration increased significantly in all groups from day 3 to day 10 but was highest in Group II. A similar trend was observed in the liver tissue but only group III increased significantly. Catalase activity was inhibited in Group II in both kidney and liver tissues and was significantly lower than test group. Serum $\mathrm{Na}^{+}$ decreased and $\mathrm{K}^{+}$increased respectively but Group III were comparable to the Group I. Creatinine concentration increased in all groups but was highest in Group II though it was not significant. ALP activity was significantly higher $(p<0.05)$ in Group III on day 3 compared to Group I but was not significantly different $(p>0.05)$ on day 10 . The results of this study suggests that ethanol extract of Aframomum angustifolium seeds can accelerate the in vivo repair of bromate induced hepato- and reno- toxicity in Wistar rats.
\end{abstract}

KEYWORDS: Aframomum angustifolium, bromate toxicity, malondialdehyde, antioxidant, phytochemicals.

\section{INTRODUCTION}

The oxidative property of potassium bromate $\left(\mathrm{KBrO}_{3}\right)$ is the chemical basis for its use in cosmetic production such as in permanent hair weaving solutions as well as flour maturation and dough conditioning in bread and other confectionery products. It has been reported as a nephrotoxin. Studies support this tumorigenic and carcinogenic property of bromate in rats and its activity as a nephrotoxin in humans and experimental animals (Kurokawa et al., 1986). Its use in bread and confectionery production has been banned in Nigeria by the Federal Government since 1993 based on its reported toxicity (Ekop et al., 2008; Oloyede and Sunmonu, 2009). However, decades after the ban, qualitative and quantitative screening of these products from different parts of the country indicate continued use (Okolie and Osarenren, 2003; Okolie et al., 2005, Emeje, et al., 2010; Oyekunle et al., 2014; Dada et al., 2017). Reports on $\mathrm{KBrO}_{3}$ dose on induction on renal oxidative stress vary. The oral lethal dose $\left(L_{50}\right)$ of potassium bromate has been established in wistar rat as 160-190 mg/kgbw (Oyewo et al., 2013). Higher doses have been used in some studies with no lethality (Wolf et al., 1998). The mechanism of action is the induction of oxidative stress mediated by several enzyme systems (Halliwell and Gutteridge, 1999). This suggests that the supply of safe and effective natural free radicalscavengers may reduce the toxic effect as well as support the treatment of

Ebhohimen, I. E., Department of Chemical Sciences, Samuel Adegboyega University, Ogwa, Edo State, Nigeria.

Ebhomielen, J. O., Department of Chemical Sciences, Samuel Adegboyega University, Ogwa, Edo State, Nigeria.

Edemhanria, L., Department of Chemical Sciences, Samuel Adegboyega University, Ogwa, Edo State, Nigeria.

Osagie, A. O., Department of Medical Biochemistry, University of Benin, Benin City, Edo State, Nigeria.

Omoruyi, J. I., Crop Improvement and Management Department, Rubber Research Institute of Nigeria, Iyanomo, Edo State, Nigeria. 
damage induced by exposure to bromate. Single doses of $\mathrm{KBrO}_{3}$ have been reported to induce toxicity and the deleterious effect can be ameliorated by natural antioxidants (Ahmad et al., 2012). The use of synthetic antioxidants is discouraged due to uncertainty about their toxicity (Kang, 2016). Natural antioxidants have gained relevance in combating oxidative stress. Some compounds such as rutin and taurine have been reported to demonstrate protective effects against $\mathrm{KBrO}_{3}$ induced toxicity (Ahmad et al., 2013; Khan and Sultana, 2005; Khan et al., 2012).

Aframomum angustifolium was selected for this study based on the fact that it is not a threatened species (Crook, 2013), cheap and is consumed as a spice in many local delicacies. A previous study revealed that the antioxidant property of the extract is not lost after heat processing like cooking (Ebhohimen et al., 2017b). This study explored the effect of ethanol extract of Aframomum angustifolium seeds in the management of toxicity induced by bromate exposure.

Methods

\section{SAMPLE PREAPARATION}

Dry Aframomum angustifolium seeds were purchased from a local merchant in Ebelle Market, Igueben Local Government Area, Edo state, Nigeria and were authenticated in the Department of Biological Sciences, Samuel Adegboyega University, Ogwa, Edo State.

The seeds were air dried for five $(5)$ days at $\left(30^{\circ} \mathrm{C}\right)$, and thereafter pulverized using a mechanical blender into fine powder. Extraction was done by cold maceration in ethanol for 72 hours as described by Prajapati and Patel (2015). The extract was concentrated using a rotatory evaporator. The concentrates were dried to powder using silica gel in a desiccator. The dry powder was stored in air-tight bottles at room temperature and was used subsequently for the study.

\section{EXPERIMENTAL ANIMALS}

Eighteen male Wistar rats weighing 140-200 g obtained from animal house, Department of Biochemistry, University of Benin, Edo state, Nigeria, were used for the study. They were acclimatized for one week with free access to food and water. The animals were maintained at room temperature with 12 hours light/dark cycles.

The animals were randomly divided into three groups of six rats each. Group I served as normal control and received distilled water orally with the aid of a gavage. Group II served as positive control and received an acute dose of potassium bromate $(400 \mathrm{mg} / \mathrm{kgbw})$ once while Group III served as test and received same single acute dose of bromate and thereafter $750 \mathrm{mg} / \mathrm{kgbw}$ of ethanol extract of Aframomum angustifolium seeds for 10days after administration of bromate. On day 3 , half the animals in each group were sacrificed while the remaining half was sacrificed on day 10 . The animals were sacrificed under light ether anaesthesia.

\section{COLLECTION OF BLOOD AND TISSUE SAMPLES}

Blood samples were collected from each animal by cardiac puncture into sample tubes. Serum used for analysis was obtained by centrifuging the blood after clotting. The liver and kidney were isolated, blotted free of blood, rinsed in ice-cold physiological saline and homogenized in ice-cold $0.01 \mathrm{M}$ potassium phosphate buffer $(0.1 \mathrm{M}, \mathrm{pH} 7.4)$ to give a $10 \%$ homogenate. Aliquots of the tissue homogenate were suitably processed for the assessment of the following biochemical parameters (Devendran and Balasubramanian, 2011).

\section{CHEMICALS AND REAGENTS}

Chemicals and reagents used in this research work were of analytical grade. Reagent kits for creatinine, ALT, ALP, BIL (Randox, UK), potassium and sodium ions (Teco Diagnostics, USA) were purchased from Pyrex Scientific, Benin City, Edo State.

\section{METHODS}

All parameters were measured by spectrophotometry using assay procedures described in the assay kits. Catalase activity and MDA concentration were measured as described by Cohen et al. (1970) and Buege and Aust (1978) respectively.

\section{STATISTICAL ANALYSIS}

The experimental results obtained are presented as means. Statistical analysis was done using IBM SPPS Statistics 23. $p<0.05$ was considered statistically significant.

\section{RESULTS}

The effect of ethanol extract of Aframomum angustifolium seeds on hepato- and renal toxicity induced by single dose of $\mathrm{KBrO}_{3}$ was examined. The dose of $\mathrm{KBrO}_{3}$ used in this study was toxic but not lethal. The effect of the extract on $\mathrm{KBrO}_{3}$-induced hepatotoxicity and nephrotoxicity was evaluated from the concentration of MDA and catalase activity in liver and kidney tissues, serum levels of creatinine, sodium, potassium and bilirubin as well as activity of ALT and ALP. The results are presented in Figures 1-10.

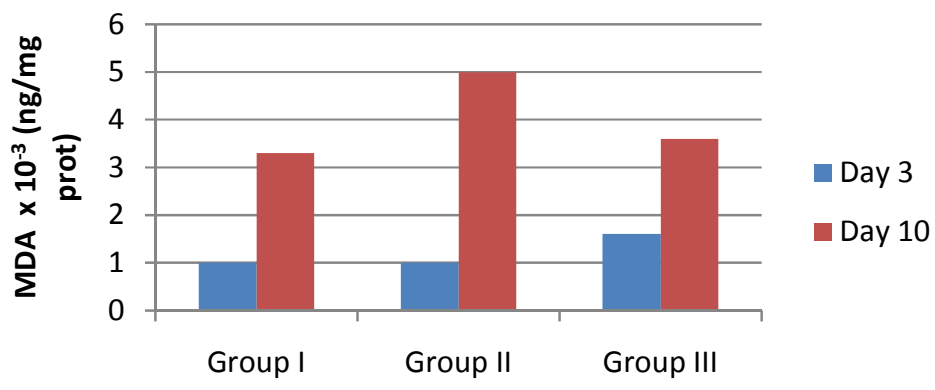

Fig 1: Effect of $\mathrm{KBrO}_{3}$ and the ethanol extract of Aframomum angustifolium seeds on MDA concentration in kidney tissue 


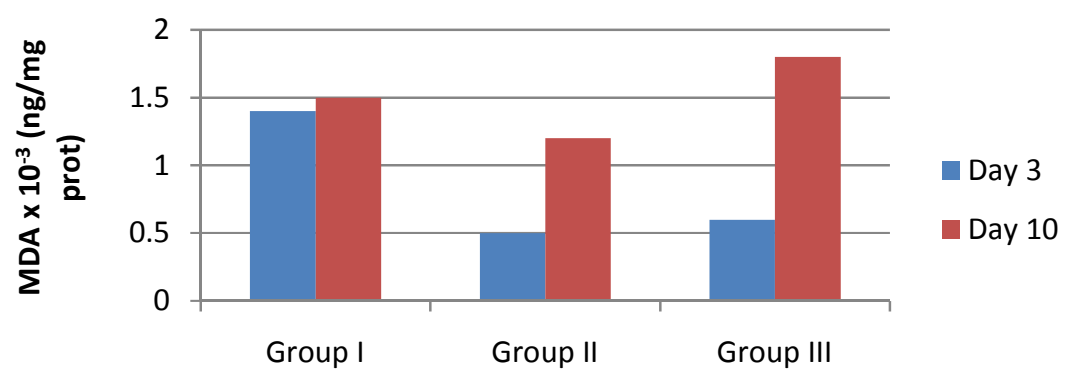

Fig. 2: Effect of $\mathrm{KBrO}_{3}$ and the ethanol extract of Aframomum angustifolium seeds on MDA concentration in liver tissue.

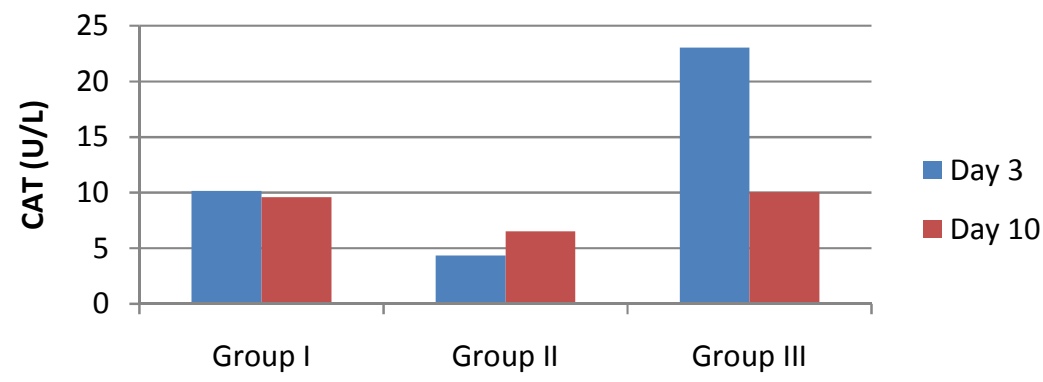

Fig. 3: Effect of $\mathrm{KBrO}_{3}$ and the ethanol extract of Aframomum angustifolium seeds on CAT activity in kidney tissue.

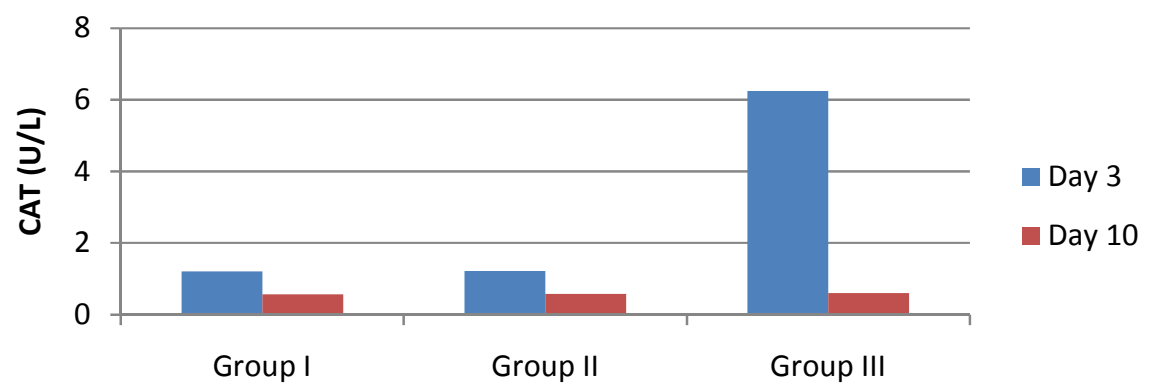

Fig. 4: Effect of $\mathrm{KBrO}_{3}$ and the ethanol extract of Aframomum angustifolium seeds on CAT activity in liver tissue.

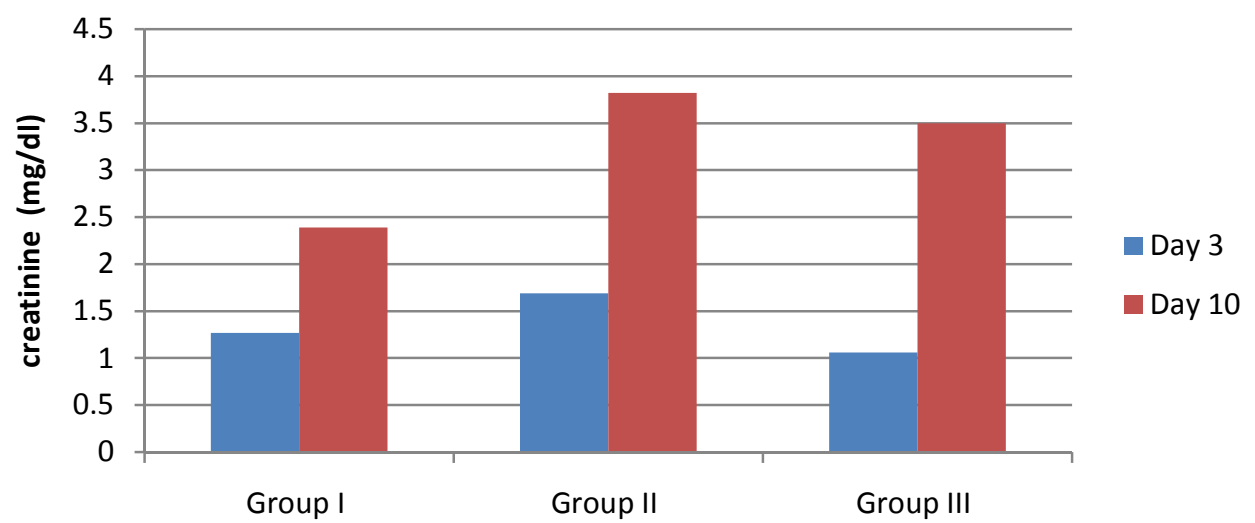

Fig. 5: Effect of $\mathrm{KBrO}_{3}$ and the ethanol extract of Aframomum angustifolium seeds on serum creatinine concentration. 


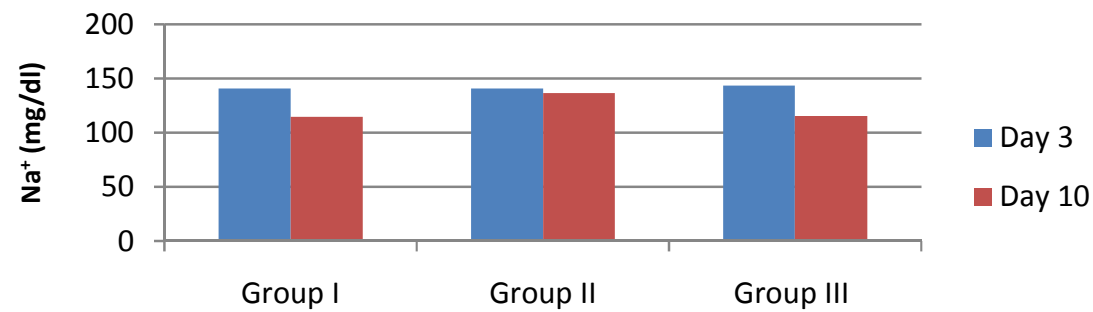

Fig. 6: Effect of $\mathrm{KBrO}_{3}$ and the ethanol extract of Aframomum angustifolium seeds on serum $\mathrm{Na}^{+}$concentration.

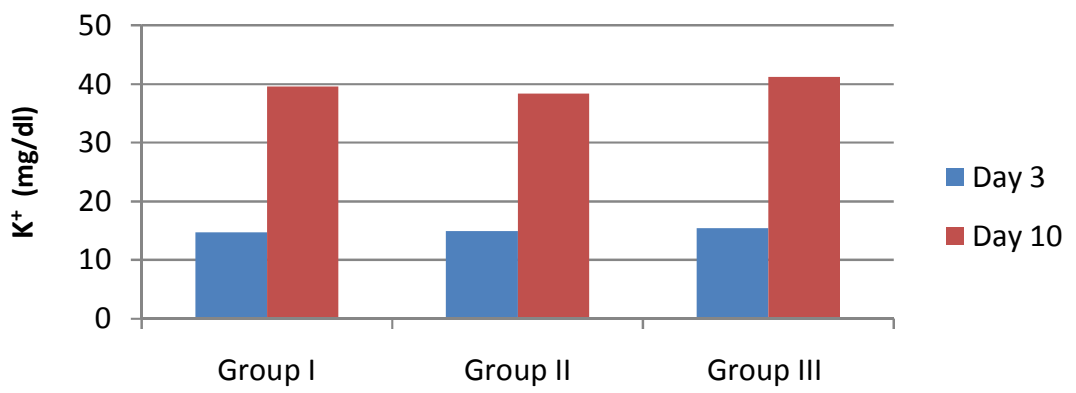

Fig. 7: Effect of $\mathrm{KBrO}_{3}$ and the ethanol extract of Aframomum angustifolium seeds on serum $\mathrm{K}^{+}$concentration.

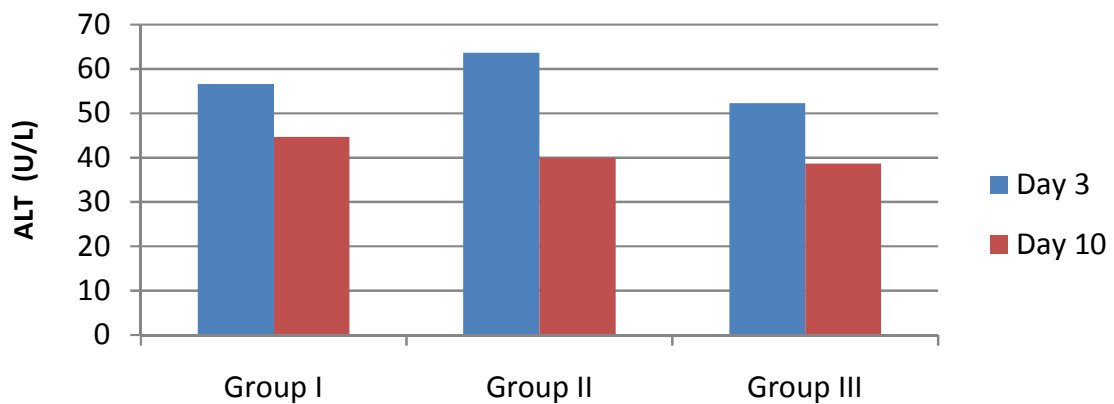

Fig. 8: Effect of $\mathrm{KBrO}_{3}$ and the ethanol extract of Aframomum angustifolium seeds on serum ALT activity.

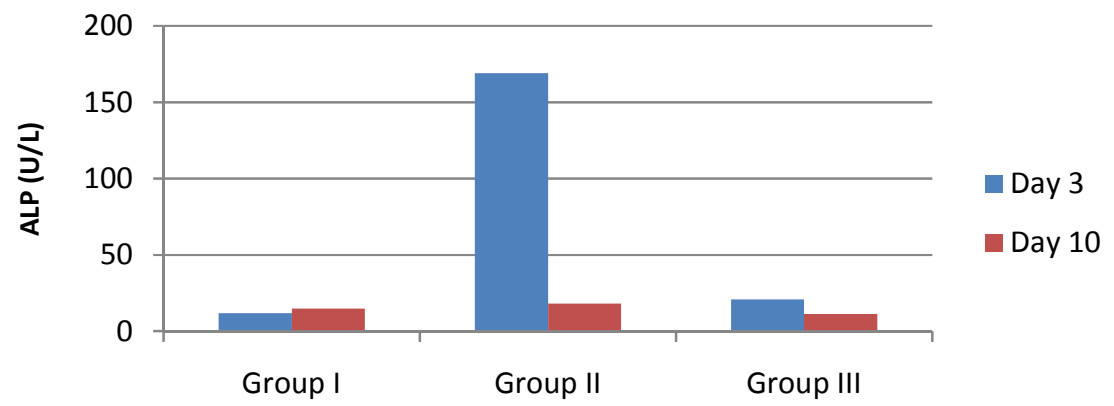

Fig. 9: Effect of $\mathrm{KBrO}_{3}$ and the ethanol extract of Aframomum angustifolium seeds on serum ALP activity 


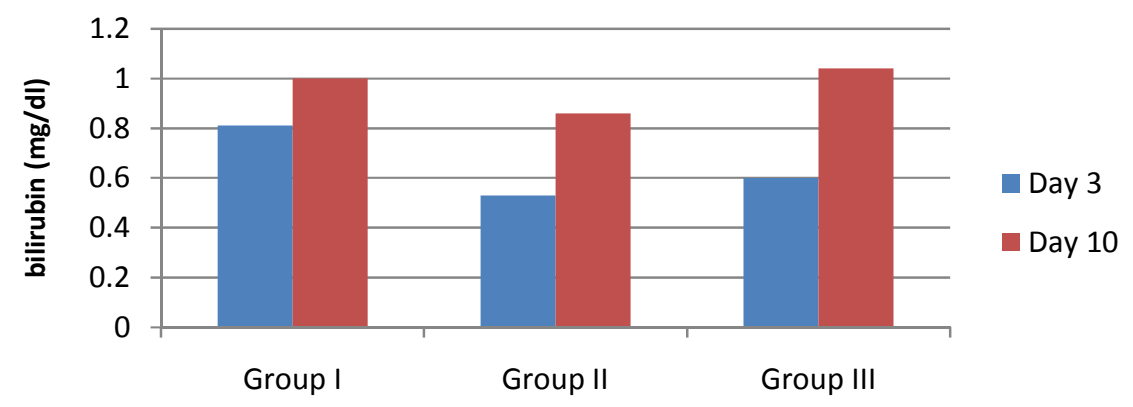

Fig. 10: Effect of $\mathrm{KBrO}_{3}$ and the ethanol extract of Aframomum angustifolium seeds on serum bilirubin concentration

\section{DISCUSSION}

Supplementation with dietary antioxidants is a promising means to strengthen antioxidant defense and oxidative damage repair systems. Currently, phytochemicals are playing lead roles due to their potency in the reduction of oxidative stress in vivo (Amadi et al., 2016; Ebhohimen et al., 2017a).

In this study, the antioxidant effect of the ethanol extract of Aframomum angustifolium seeds was used as a potential repair agent against toxicity induced by $\mathrm{KBrO}_{3}$, a known hepato- and nephrotoxic agent. Aframomum angustifolium was selected based on factors such as availability, common use as a dietary spice and reported non-toxicity (Anywar and Kirimuhuzya, 2015). A study by Ebhohimen et al. (2017b) revealed that the antioxidant property of the ethanol extract is not completely destroyed by heat treatment such as cooking.

Several protective agents against $\mathrm{KBrO}_{3}$-induced toxicity have been reported. Rutin and taurine, reported to have antioxidant capacities have been studied (Khan et al., 2012; Ahmad et al., 2013; Ben et al., 2016). Their effect on bromate toxicity can be easily explained since the mechanism of $\mathrm{KBrO}_{3}$ induced toxicity is the production of ROS (Nishioka et al., 2006; Spassova et al., 2015). Lipid peroxidation is a complex process that damages the cell structure and function. Peroxidation of lipids of cell membrane initiates a loss of membrane integrity, membrane bound enzyme activity and causes cell lysis (Pryor and Squadrito, 1995). Malondialdehyde is a product of lipid peroxidation and is commonly used as a biomarker (Ayala et al., 2014).

Results for MDA concentration obtained in this study are presented in Figures 1 and 2. In kidney tissue, MDA concentration increased after day 3 to day 10 in all study groups. It was significant $(p<0.05)$ in Groups I and II and was highest in Group II. Similar observations were reported by Kurokawa et al., (1990), Khan and Sultana 2004 as well as Naglaa et al., (2016). In the liver tissue, concentrations of MDA in all study groups though lower than that observed in the kidney tissues, increased in all study groups from day 3 to day 10 but were not significant. The observed difference in MDA concentration in liver and kidney tissue may be attributed to differences in lipid composition or action of antioxidants. Jurczuk et al., (2004) reported the administration of ethanol, increased the activity of superoxide dismutase in the kidney while the activity decreased in the liver. MDA concentration increased in the liver and was unchanged in the kidney.

Catalase catalyzes the decomposition of hydrogen peroxide into less-reactive gaseous oxygen and water
1999). It is a common enzyme found in nearly all living organisms exposed to oxygen. In this study, catalase activity in the kidney was not altered in the normal control group (Fig. 3). Positive control exposed to an acute dose of bromate had the lowest catalase activity on day 3 and was significantly lower $(p<0.05)$ compared to Groups I and III. On day 10, catalase activity in Group II increased but was still lower than the other groups though not significant. High doses of prooxidants have been reported to interfere with the activity of antioxidant enzymes (Altoom et al., 2018). Observed catalase activity in the test group treated with extracts was significantly higher $(p<0.05)$ than the other groups on day 3 but was at the same level as the normal control on day 10. The administration of extract may have contributed to the activity surge on day 3. A similar trend was observed in the liver tissue (Fig. 4). Catalase activity in the treated group was significantly higher after day III compared to Groups I and II. After day 10, catalase activity across the study groups reduced and were not significantly different. Like MDA, catalase activity was higher in the kidney suggesting higher oxidative activity in the kidney. This supports previously published reports that bromate is a specific nephrotoxin (Ahmad et al., 2013; Oseni et al, 2015).

Serum creatinine concentration is a reliable indicator of kidney function. Bromate treated group had higher serum creatinine concentration on day 3 . It was not significantly different from Groups I and III. On day 10, creatinine concentration increased in all groups ( $p>$ 0.05 ) but was highest in Group II. Significant alterations in serum creatinine concentration after bromate exposure was reported by Ahmad et al. (2013). In that study, taurine was used as the chemo-protectant against bromate nephrotoxicity and significant alterations were seen after administration of $\mathrm{KBrO}_{3}$ alone compared to the control group. Altoom et al. (2018) also reported a dose dependent increase in serum creatinine concentration after oral administration of bromate. The elevated creatinine level may signify impaired kidney function or kidney disease. In this study, creatinine concentration in Group III decreased from day 3 to day 10 of oral administration of the extract.

Sodium, one of the body's important extracellular electrolytes have various functions especially in the kidney where it regulates blood pressure and blood volume and also regulates the acid-base balance of blood and body fluids (Polychronopoulou et al., 2019). Sodium concentration across the groups were not significantly different on day 3 . Serum concentration dropped in all groups but was not significant in the positive control group. Sodium and fluid buildup in the 
pressure. This results in reduction of kidney function and the accumulation of waste in the body. Sodium concentration in the normal control and test groups were not significantly different on day 10 .

Potassium is an important electrolyte necessary for the normal functioning of all cells, tissues and organs in biological systems. The kidneys control the level of potassium in the body excreting excess amounts through urine. There is a dearth of information on bromate induced toxicity on potassium concentration in serum. In this study, potassium concentration in serum increased significantly in all groups.

Alanine aminotransferase (ALT) is found in plasma and in various body tissues but is most common in the liver. It catalyzes the two parts of the alanine cycle. Serum ALT level and the ratio is commonly measured as biomarkers for liver health. Elevated levels of ALT often suggest the existence of other medical problems such as viral hepatitis, diabetes and liver damage. In this study, ALT activity was not significantly different across the study groups after day 3 . The activity of the enzyme decreased across all groups on day 10 but was lowest in the treated group. Alkaline phosphate (ALP) is also found in several tissues throughout the body. The highest concentrations of ALP are present in the bone and liver. Elevated levels of ALP in the blood are most commonly caused by liver disease or bone disorders. In this study, ALP activity was significantly higher in the positive control group on day 3 . After day 10 , activity was still higher but was significantly lower compared to day 3 and was in the same range with the other groups. Oseni et al., (2015) also reported increased activity of ALT and ALP following administration of $30 \mathrm{mg} / \mathrm{kgbw}$ bromate for two weeks. However, Ahmad et al., (2013) reported decreased ALP after exposure to bromate alone. In that study, the control and the extract treated group had significantly higher ALP activity.

Bilirubin is a yellow compound that occurs in normal catabolic pathway that breaks down haem. This catabolism is a necessary process in the clearance of waste products that arise from the destruction of aged red blood cells. The red blood cells have a lifespan of about 120 days and are continually renewed. Red blood cells contain haemoglobin and it is this that gets broken down into bilirubin and other substances. The bilirubin is carried to the liver by albumin. The levels of bilirubin in the blood can indicate the health of liver. The bromate treated groups had lower bilirubin concentration on day 3. Positive control group was significantly lower than normal control group. Although bilirubin concentration was still lower in this group on day 10, it was not significantly different from the normal control and treated groups.

\section{CONCLUSION}

The observed results obtained for biochemical parameters in this study suggests that ethanol extracts of Aframomum angustifolium seeds support the in vivo repair of potassium bromate induced toxicity in Wistar rats. This may be due to the established antioxidant capacity of its phytochemical components.

The enforcement of ban should be reinvigorated. Adequate awareness on the toxicity as well as qualitative tests procedure should be created by relevant agencies regulating food and cosmetics production.

It is therefore suggested that natural phytochemical sources be consumed regularly to ameliorate the deleterious effect of pro-oxidants man is continually exposed to.

\section{REFERENCES}

Ahmad, M.K., Khan, A.A. and Mahmood, R., 2013. Taurine ameliorates potassium bromate-induced kidney damage in rats. Amino Acids, 45, 11091121.

Ahmad, M.K., Naqshbandi, A., Fareed, M. and Mahmood, R., 2012. Oral administration of a nephrotoxic dose of KBRO3, a food additive alters renal redox and metabolic status and inhibits brush border membrane enzymes in rats. Food Chemistry, 134, 980-985.

Altoom, N.G., Ajarem, J, Allam, A. A., Maodaa, S. N., and Abdel-Maksoud, M.A., 2018. Deleterious effects of potassium bromate administration on renal and hepatic tissues of Swiss mice. Saudi Journal of Biological Sciences, 25, 278-284.

Amadi, S. W., Zhang, Y. and Wu, G., 2016. Research progress in phytochemistry and biology of Aframomum species. Pharmaceutical Biology, 54(11):2761-2770.

Anywar, G.U. and Kirimuhuzya, C., 2015. Phytochemical profile and antibacterial activity of crude extracts of the pod of Aframomum angustifolium (Sonn.) K. Schum. European Journal of Biological Research, 5 (2), 36-41.

Ayala, A., Muñoz, F. M. and Argüelles, S., 2014. Lipid Peroxidation: Production, metabolism, and signaling mechanisms of malondialdehyde and 4-hydroxy-2-nonenal. Oxidative Medicine and Cellular Longevity, 2014,1-31.

Ben, S.H., Driss, D., EllouzChaabouni, S., Boudawara, T., Zeghal, K.M, Hakim, A. and Ben A.I., 2006. Efficacy of oligonol, catechin and (-)epigallocatechin 3-O-gallate in modulating the potassium bromate-induced renal toxicity in rats. Toxicology, 226, 181-187.

Buege, J. and Aust, S.D., 1978. Microsomal Lipid Peroxidation. In: Methods in Enzymology. Colowick SP, Kaplan NO (eds). Academic Press, New York. pp. 302-311.

Cohen, G. J., Dembiec, D. and Marcus, J., 1970. Measurement of catalase activity in tissue extracts. Analytical Biochemistry, 34:30-38.

Crook, V., 2013. Aframomum angustifolium. The IUCN Red List of Threatened Species 2013: Retrieved February 9, 2019, from http://www.iucnredlist.org/details/biblio/4439242 $8 / 0$.

Dada, E. O., Akinola, M. O., Adewole, O. I., Ayobami, P. T. and Braimoh, B. E., 2017. Comparative levels of bromate and metals in bread loaves obtained from corporate and local bakeries in two 
communities of Lagos Nigeria. FUW Trends in Science and Technology Journal, 2, 861-864.

Devendran, G. and Balasubramanian, U., 2011. Biochemical and histopathological analysis of aflatoxin induced toxicity in liver and kidney of rat. Asian Journal of Plant Science and Research, 2011, 1 (4):61-69.

Ebhohimen, I.E., Awojide, S., Ebhohimen, K. and Edemhanria, L., 2017a.In silico investigation of biochemical and pharmacological activity of the oxidation products of ascorbic acid. Nigerian Journal of Pure \& Applied Sciences, 30: 31163121.

Ebhohimen, E.I., Edemhanria, L., Ekozin, A. and Okolie, N.P., 2017b. Effect of heat treatment on the antioxidant capacity of aqueous and ethanol extract of Aframomum augustifolium seed. Tropical Journal of Natural Product Research, 1(3): 125-128.

Ekop, A.S., Obot, I.B. and Ikpatt, E.N., 2008. AntiNutritional Factors and Potassium Bromate Content in Bread and Flour Samples in Uyo Metropolis, Nigerian. European Journal of Medical Chemistry, 5:736-741.

Emeje, M. O., Ofoefule, S. I., Nnaji, A. C., Ofoefule, A. U. and Brown, S. A., 2010. Assessment of bread safety in Nigeria: Quantitative determination of potassium bromate and lead. Academic Journals, 4: $394-397$.

Halliwell, B., 1999. Oxygen and nitrogen are procarcinogens. Damage to DNA by reactive oxygen, chlorine and nitrogen species: measurement, mechanism and the effects of nutrition. Mutation Research, 443: 37-52.

Halliwell, B. and Gutteridge, J.M.C., 1999. Free Radicals in Biology and Medicine. In: Halliwell, B. and Gutteridge, J.M.C., Eds., Free Radicals in Biology and Medicine, 3rd Edition, Oxford University Press, Oxford. Pp. 1-25.

Jurczuk, M., Brzoska, M.M., Moniuszko-Jakoniuk, J., Gałazyn-Sidorczuk, M., Kulikowska-Karpinska, E., 2004. Antioxidant enzymes activity and lipid peroxidation in liver and kidney of rats exposed to cadmium and ethanol. Food and Chemical Toxicology, 42(3): 429-38.

Kang S., 2016. Ethanol Extracts from Mistletoe (Viscum album L.) Act as Natural Antioxidants and Antimicrobial Agents in Uncooked Pork Patties during Refrigerated Storage. Asian-Australasian Journal of Animal Science, 29(1): 109-118.

Khan, N. and Sultana, M., 2004. Abrogation of Potassium bromate induced renal oxidative stress and tumor promotion response by Soy isoflavones in Wistar rats. Toxicology. 201: 17384.
Khan, N., Sultana, M., 2005. Inhibition of potassium bromate-induced renal oxidative stress and hyperproliferative response by Nymphaea alba in Wistar rats. Journal of Enzyme Inhibition and Medicinal Chemistry, 20: 275-283.

Khan, R.A., Khan, M.R. and Sahreen, S., 2012. Protective effects of rutin against potassium bromate induced nephrotoxicity in rats. BMC Complementary and Alternative Medicine, 12: 204.

Kurokawa, Y., Aoki, S. and Matsushima, Y., 1986. Dose response studies on carcinogenicity of potassium bromate in F344 rats after long term oral administration. Journal of the National Cancer Institute, 77: 977-982.

Kurokawa, Y., Maekawa, A., and Hayashit, Y., 1990. Toxicity and Carcinogenicity of Potassium Bromate-A New Renal Carcinogen. Environmental Health Perspectives87:309-335.

Naglaa B., Gehan,S. and Eman, A., 2016. Effect of potassium bromate on the liver of adult Male albino rat and a possible protective role of vitamin C: Histological, immunohistochemical and biochemical study. The Anatomical Record, 299:1256-1269.

Nishioka, H., Fujii, H., Sun, B. and Aruoma, O., 2006. Comparative efficacy of oligonol, catechin and ()-epigallocatechin 3-O-gallate in modulating the potassium bromate-induced renal toxicity in rats. Toxicology 226: 181-187.

Okolie, N. P. and Osarenren, E. J., 2003. Toxic bromate residues in nigerian bread. Bulletin of Environmental Contamination and Toxicology, 70:443-446.

Okolie, N. P., Ukun, M. E. and Onyema, E. O., 2005. Bromate residues in some popular baked products in relation to the sustained antibromate campaign in nigeria. Bulletin of Environmental Contamination and Toxicology, 74: 894-898.

Oloyede, O.B. and Sunmonu, T.O., 2009. Potassium bromate content of selected bread samples in Ilorin, Central Nigeria and its effect on some enzymes of rat liver and kidney. Food Chemical Toxicology, 4: 2067-2070.

Oseni, O., Olagboye, S., and Idowu, A., 2015. Potassium Bromate Induced Renal Toxicity in Wistar Albino Rats: Effects of Aqueous Extract of Nutmeg (Myristica fragrans Houtt). British Journal of Medicine and Medical Research, 5: 1547-1556.

Oyekunle, J. A. O., Adekunle, A. S., Ogunfowokan, A. O., Olutona, G. O. and Omolere, O. B., 2014. Bromate and trace metal levels in bread loaves from outlets within lle-Ife metropolis, Southwestern Nigeria. Toxicology Reports, 1, 24-230. 
Oyewo, O.O., Onyije, F.M. and Awoniran, P. O., 2013. Hepatotoxic effect of potassium bromate on the liver of wistar rats. Journal of Morphological Sciences, 30, 107-114.

Polychronopoulou, E., Braconnier, P. and Burnier, M., 2019. New insights on the role of sodium in the physiological regulation of blood pressure and development of hypertension. Frontiers in Cardiovascular Medicine, 6: 1-9.

Prajapati, D. D. and Patel, N. M., 2015. Assessment of antioxidant potential of Holoptelia integrifolia Roxb leaves by in vitro. American Journal of Food Science and Health 1: 1-9.
Pryor, W., Squadrito, G.L. and Friedman, M., 1995. The cascade mechanism to explain ozone toxicity: the role of lipid ozonation products. Free Radical Biology and Medicine, 19: 935-941.

Spassova, M.A., Miller, D.J. and Nikolov, A.S., 2015. Kinetic modeling reveals the roles of reactive oxygen species scavenging and DNA repair processes in shaping the dose-response curve of $\mathrm{KBrO}_{3}$ - induced DNA damage. Oxidative Medicine and Cellular Longevity, 2015,1-12.

Wolf, D.C., Crosby, L.M., George, M.H., Kilburn, S.R., Moore, T.M., et al., 1998. Time- and dose dependent development of potassium bromateinduced tumors in Male Fischer 344 Rats. Toxicologic Pathology, 26: 724-729. 